\title{
UNA NUEVA MIRADA A LAS PRESTACIONES MUTUAS
}

\author{
Pablo Cornejo Aguilera* \\ Universidad de Chile
}

RESUMEN: El presente trabajo pretende introducir una línea de argumentación alternativa a la tradicionalmente desarrollada por la doctrina nacional a fin de justificar la manera como el legislador resuelve los conflictos que surgen como consecuencia de las traslaciones patrimoniales producidas por las decisiones de inversión y explotación de los bienes, cuando no existe una correlación entre la persona que goza de una titularidad protegida por una regla de propiedad y aquella que se encuentra en una posición fáctica que le permite ejercer materialmente el contenido de ese derecho; la cual, sin despreciar la importancia que presenta una argumentación de principios basada en la justicia, pondrá énfasis en el objetivo de bienestar social que subyace a nuestras reglas legales.

Palabras Clave: Enriquecimiento injustificado, propiedad, posesión.

ABSTRACT: This article introduces an alternative argument to the traditional national doctrine regarding decision-making for investments and exploitation of goods. The alternative argument justifies the decision-making process of the legislator per the conflicts that arise from hereditary changes in investment and exploitation of goods. The alternative argument is not used when there is a co-relationship between the owner protected by rule of property and the individual with force of establishment that allows him to materially exercise a right of ownership; nevertheless without undermining the importance of the principle of justice and social welfare.

Key words: Unjust enrichment, property, possession.

\section{INTRODUCCIÓN}

Pese a su antigüedad, las reglas de las prestaciones mutuas contenidas en el Código Civil chileno (en adelante CCch) no han sido objeto de un análisis crítico por parte de la doctrina nacional. Por el contrario, en los diversos textos consagrados al estudio de los derechos reales, la exposición que se presenta suele ser meramente descriptiva ${ }^{1}$, siendo pocos los autores que se cuestionan sobre su justificación ${ }^{2}$ y menos aún los que se preguntan por la forma como estas promueven el bienestar social. Por el contrario, una somera revisión de los autores nacionales permite apreciar que la importancia de esta institución se ha circunscrito a considerarla como una expresión del principio del enriquecimiento sin causa, siendo en consecuencia su análisis una aplicación práctica de los razonamientos desarrollados con ocasión de este principio ${ }^{3}$.

\footnotetext{
Egresado de Derecho, Universidad de Chile. Ayudante del Departamento de Derecho Privado.

v. Alessandri Rodríguez, Arturo; Somarriva Undurraga, Manuel; Vodanovic H., Antonio. Tratado de los Derechos Reales -6a Edición- Santiago, Chile: Editorial Jurídica de Chile, 1997, pp 293-301.; RozAS VIAL, Fernando. Los Bienes - $3^{\text {a }}$ Ed. Santiago: LexisNexis 2004, pp 380-385. PeñAILILlo ArÉVAlo, Daniel. Los Bienes. La Propiedad y Otros Derechos Reales. Santiago: Editorial Jurídica de Chile, 2009, pp. 542-542.

2 Una excepción es don Claro Solar, Luis. Explicaciones de Derecho Civil Chileno y Comparado. Santiago, Chile: Editorial Nascimento, 1935. pp. 429 y ss.

3 FueYo LANeri, Fernando. "El Enriquecimiento sin Causa a Expensas de Otro, con Especial Acento en su Doctrina General y Atípica”. En su: Instituciones de Derecho Civil Moderno. Santiago, Chile: Editorial Jurídica de Chile, 1990, pp. 445-446;
} 
Con todo, debemos advertir que no es el objetivo de este trabajo pretender encontrar una justificación a esta institución que reemplace las concepciones relacionales de justicia desarrolladas a fin de explicarla. Pretender realizar esa labor resultaría doblemente estéril, desde el momento que no solo se trataría de una empresa que supera con creces nuestras capacidades, sino que además carecería de la visión de conjunto que exige la complejidad de nuestras prácticas sociales ${ }^{4}$, en las cuales, producto de su larga evolución, se plasman una serie de principios y políticas que muchas veces carecen de una estrecha relación o nos pueden llegar a parecer contradictorios o incoherentes. El objetivo que nos planteamos es mucho más modesto. Simplemente trataremos de dar una nueva mirada a las reglas legales referidas a las prestaciones mutuas, esta vez desde una perspectiva externa, tratando de determinar cuáles son los incentivos que sus prescripciones proporcionan a nuestras decisiones de utilización de los bienes.

De la misma forma, deberemos realizar una advertencia previa. El objetivo del presente trabajo es realizar un análisis de las reglas de las prestaciones mutuas, razón por la cual se excluirán expresamente las reglas referidas a los daños. La razón de esta exclusión es simple: si bien ambas instituciones comparten un mismo lugar en la sistemática del Código Civil, resulta inconcuso que obedecen, incluso vistas desde una perspectiva jurídica, a concepciones distintas. En efecto, mientras la normativa de las prestaciones se inserta dentro de las reglas de propiedad, persiguiendo solucionar los intercambios patrimoniales no voluntarios que se han producido, suponiendo de esta forma su aplicación una afectación de la función atributiva del dominio, que no genera per se una pérdida de recursos; las reglas relativas a los daños precisamente suponen la producción de este costo hundido, razón por la cual se pueden comprender de mejor manera mirando nuestro sistema de responsabilidad civil ${ }^{5}$, siendo esta razón suficiente para evitar una tratamiento conjunto.

Como es bien sabido, el artículo 582 CCch define el dominio a través de las potestades que este derecho confiere a su titular, como "el derecho real en una cosa corporal, para gozar y disponer de ella arbitrariamente; no siendo contra la ley o contra derecho ajeno", en una definición que resulta acertada, toda vez que expresa la principal característica que asignamos

Figueroa YáñeZ, Gonzalo. El Patrimonio. Santiago, Chile: Editorial Jurídica de Chile,, 1991, p. 309; PeÑAIliLlo Arévalo, Daniel. "Enriquecimiento sin Causa. Principio de Derecho y Fuentes de Obligaciones" en: Revista de Derecho Universidad de Concepción. N²00, pp. 7-40. Concepción, Chile: Universidad de Concepción, 1996.

4 En este sentido, señala ZIMMERMANN que "En la actualidad, sin embargo, hay un sistema bastante complejo y fragmentado de motivos especificos para corregir el enriquecimiento injusto, que se han desarrollado a lo largo de los siglos de modo azaroso, y que son más el producto de accidentes históricos y de ficciones legales que el resultado de un proyecto racional". ZIMMERMANN, Reinhard. Estudios de Derecho Privado Europeo. Madrid: Civitas, 2000, p. 248. En similar sentido, refiriéndose a la responsabilidad extracontractual. Coleman, Jules. La Concepción Mixta de la Justicia Correctiva. En: Rosenkrantz, Carlos. (comp). La Responsabilidad Extracontractual. Barcelona, España: Editorial Gedisa, 2005, p. 71.

5 Sobre la distinción entre reglas de propiedad y de responsabilidad Calabresi, Guido y MELAmED, Douglas. "Reglas de Propiedad, Reglas de Responsabilidad y de Inalienabilidad: Una Vista de la Catedral” en: Estudios Públicos, No 63, pp. 347 y ss. Santiago, Chile: Centro de Estudios Públicos, 1996. 
al dominio, cual es el comprender el máximo contenido de la atribución realizada. En efecto, si existe un elemento que permite caracterizar el dominio, es el hecho que confiere la más plena titularidad sobre un bien determinado. Sin embargo, la importancia de la definición no se agota en la precisión del contenido del derecho. El codificador quiso ir más allá, incorporando en ella misma un segundo elemento, cual es su carácter absoluto. De esta forma, el dominio tiene en nuestro sistema un doble carácter absoluto, toda vez que, además de conceder una protección general, sin respecto a determinada persona, que permite como consecuencia de su naturaleza de derecho real excluir cualquier interferencia no consentida por el titular, es también absoluto en cuanto a la amplitud de las decisiones que el titular puede adoptar en lo que concierne a la manera como se utilizará el bien, las cuales no se encuentran en principio sujetas a un control externo ${ }^{6}$.

Estas características propias de los derechos reales y manifestadas de la forma más completa en el derecho de dominio, han permitido a la doctrina comprenderlas en torno a un elemento común, cual es su función atributiva ${ }^{7}$, en una interpretación jurídico-económica que guarda perfecta relación con la definición económica de la propiedad que nos proporcionan Calabresi y Melamed al señalar que una titularidad es protegida por una regla de propiedad en la medida que quien desee intervenir en el ámbito resguardado por el derecho deberá comprárselo en una transacción voluntaria ${ }^{8}$, o con lo expresado por POSNER al caracterizar los derechos de propiedad como aquellos que excluyen (en el límite) a todo el resto del mundo del uso de una cosa, excepto bajo las condiciones impuestas por el propietario?

Hasta el momento nos hemos limitado a señalar cuáles son las características que atribuimos al derecho de dominio y que nos permiten identificarlo como institución social, sin preocuparnos por el problema de su fundamentación. En efecto, si admitimos que la propiedad privada es una institución social y no natural, inmediatamente debemos cuestionarnos sobre cuáles son las razones que nos llevan a establecer que las decisiones de inversión que recaigan sobre un determinado bien deben ser tomadas por un individuo y no por toda la comunidad de manera conjunta o a través de un organismo que represente su voluntad. Sin

\footnotetext{
6 Con todo, la amplitud y vigencia de este reconocimiento resulta cuestionada en nuestro ordenamiento actual, producto de la evolución que ha experimentado la propiedad durante el s. XX, a través de leyes que no están incorporadas en el Código Civil, las cuales dan cuenta de la importancia que se atribuye a la función social de la propiedad y los crecientes poderes regulatorios que se conceden a la Administración. TAPIA RODRíGUEZ, Mauricio. Código Civil 1855-2005. Evolución y Perspectivas. Santiago, Chile: Editorial Jurídica de Chile, 2005. pp. 136 y ss; Ríos LabBÉ, Sebastián. "Ciento Cincuenta Años de Evolución del Derecho de Propiedad”. En: Martinic, María Dora, et al. Sesquicentenario del Código Civil de Andrés Bello. Pasado, Presente y Futuro de la Codificación. Tomo I. Santiago, Chile: LexisNexis, 2005, pp. 533-570.

7 Como señalan Westermann, Harry, et al. "la función atributiva de bienes consiste en que el titular del derecho -y nadie más en contra de su voluntad- es el único que, en virtud de ese derecho, tiene el poder de actuar sobre la cosa, utilizarla, modificarla y transmitirla. cfr. 903. "La atribución tiene, pues, eficacia absoluta". WeSTERMANn, Harry, et al. Derechos Reales. Volumen I -7a Ed.- Madrid, España: Fundación Cultural del Notariado, 1998, p. 59.

8 Calabresi Guido y Melamed, Douglas, op. cit. (n. 5), p. 351.

9 Posner, Richard. El Análisis Económico del Derecho. México D.F., México: Fondo de Cultura Económica, 1998, p. 71.
} 
desconocer que la respuesta última a esta pregunta supone el desarrollo de una teoría de la justicia, para efectos del presente trabajo nos conformaremos con las respuestas que se han proporcionado desde la perspectiva del Análisis Económico del Derecho.

Desde una perspectiva económica, el reconocimiento de titularidades individuales sobre los bienes que no admiten usos competitivos se ha justificado por ser la mejor manera de maximizar el bienestar social, considerando la relación existente entre los costos de transacción que supone la adopción de las decisiones de utilización de los bienes y la forma como la utilización en concreto de estos contribuye a la generación de riqueza ${ }^{10}$. Llegado este punto cabe preguntarse, de qué manera una asignación de titularidad individual logra este objetivo. La respuesta que proporciona el Análisis Económico se basa en los incentivos que genera el reconocimiento de las titularidades para la conservación y la explotación de los bienes, pudiendo diferenciarse así entre una justificación estática y una justificación dinámica de la propiedad $^{11}$.

Como señalamos anteriormente, la factibilidad del establecimiento de una titularidad exclusiva está determinada en gran medida por la naturaleza del bien, de manera que quedan en principio excluidos los bienes que tienen un uso no competitivo, los cuales cada persona puede utilizar sin que eso signifique afectar o limitar la posibilidad de uso del resto. Sin embargo, en un mundo donde la pregunta por la justicia de nuestras decisiones sociales tiene algún sentido, esta situación es absolutamente excepcional, pudiendo advertirse que en el mundo real nuestras necesidades superan los bienes de que disponemos para satisfacerlas. Esta situación nos lleva a competir por el uso de los bienes existentes y, en caso que no existan reglas sobre la atribución, a intentar obtener el máximo beneficio en el menor tiempo posible. En otras palabras, en una situación como la descrita, no existirá un incentivo para la conservación. Como maximizadores racionales de nuestro propio interés, la inexistencia de una regla que nos asegure una retribución futura por los bienes que dejamos de consumir hoy nos lleva a intentar obtener el máximo provecho en el menor tiempo, aun cuando ello implique la afectación de la posibilidad misma de existencia de los bienes y sus frutos en el futuro. Esta situación, que es conocida en economía como la tragedia de lo común, nos indica que la única de manera de evitar que los bienes sean destruidos por la sobre utilización es asegurando que la persona que deba renunciar a obtener los beneficios hoy, los pueda obtener en

\footnotetext{
10 Por esta misma razón, constituye un presupuesto económico de la asignación exclusiva su factibilidad. En efecto, la asignación de las titularidades por sí sola no permite solucionar los problemas de incentivos y costos de transacción que justifica la propiedad privada, toda vez que siempre se requerirá de un mínimo de intervención social destinada a proteger la asignación realizada. De esta manera, cuando nos encontremos con bienes que admiten usos competitivos sin detrimento (no existe el problema de la escasez) o que no admitan la exclusión a un costo razonable, la solución socialmente eficiente será negar la existencia de una titularidad exclusiva, permitiendo que cada uno de sus miembros utilice el bien libremente. Se trata, como puede apreciarse, del caso de los bienes públicos. POSNer, Richard, op. cit.(n. 9), pp. 40-43; CoOTER, Robert y Ulen, Thomas. Derecho y Economía. México D.F., México: Fondo de Cultura Económica, 1998, pp. 143-147.

11 Cfr. POSNER, Richard, op. cit.(n. 9), pp. 37-39.
} 
el futuro. Han sido estas las razones que han permitido justificar la existencia de la propiedad privada desde una perspectiva estática.

Sin embargo, lo señalado hasta el momento no nos permite comprender a cabalidad el problema de la creación de incentivos para la conservación de las cosas. Los bienes no solamente pueden afectarse por la explotación que de ellos realicen las personas, sino que se ven sujetos también a deterioros provenientes de causas externas, debiendo ser reparados a fin que sigan prestando su utilidad. Precisamente, este es el segundo incentivo que genera la perspectiva estática de la propiedad: permite a las personas realizar inversiones con la finalidad de conservar el valor de los bienes, las cuales no serían realizadas bajo un esquema de ausencia de derechos. En este sentido, como ha señalado Shavell:

"when durable things may be taken from individuals, they will not benefit from improving them (if a machine would be taken from an individual, he will noy have an incentive to mantain it well). When, however, individuals hold possessory rights in durable things, they will have an optimal motive to improve the things because they will posses the things in the future and therefore be able to enjoy the gains from maintenance and improvements. [...] Moreover, the socially optimal improvement in durable things will be promoted noy only by possessory rights, but also by rights to transfer things. Notably, possessors will often transfer things by selling them and sales prices will generally reflect improvements made in things. Because present owners will anticipate this, they will be led to make appropiate improvements for the advantage of future owners" 12 .

Con todo, la justificación de las reglas de propiedad se encontraría incompleta si solamente mirásemos a los incentivos para la conservación de los bienes. En toda economía basada en el intercambio y que presenten una especialización de funciones, la riqueza generada por los rendimientos que las cosas producen sin la necesidad de la intervención humana es mínima, siendo por regla general necesario invertir tiempo, dinero y trabajo para poder obtener beneficios de los bienes, tratándose de esfuerzos que ningún hombre estaría dispuesto a realizar si no existe una regla que le permita apropiarse de sus resultados. Precisamente, es esta circunstancia la que ha permitido construir la segunda justificación de la propiedad privada que, estrechamente vinculada con la función atributiva de los bienes, nos dice que se trata de una institución necesaria a fin de permitir que se realicen inversiones tendientes a la generación de nuevas riquezas. Como ocurre en el ejemplo propuesto por Posner ${ }^{13}$, en

\footnotetext{
12 SHAVELL, Steven. Foundations of Economic Analysis of Law. Cambridge, Massachussetts: The Belknap Press of Harvard University Press, 2004 p. 17

13 POSNER, Richard, op. cit. (n. 9), p. 38.
} 
la sociedad no existirían granjeros que cultiven la tierra si llegado el tiempo de la cosecha no tienen derecho a excluir de los beneficios a quienes no colaboraron. De esta forma, ante la ausencia de reglas de propiedad deberíamos limitarnos a aquellas formas de aprovechamiento de los bienes que implican una inversión preparatoria menor, las cuales generalmente no son las que crean mayor riqueza ${ }^{14}$.

Sin embargo, en la mayoría de los países que integran nuestra tradición jurídica no es posible la consecución de los beneficios sociales que justifican la asignación de una titularidad exclusiva meramente recurriendo a la existencia de esa titularidad, conforme a las reglas legales que definen los modos de adquirir el dominio. En efecto, en un sistema como el chileno, resulta económicamente inviable supeditar la eficacia atributiva de la propiedad a la efectiva concurrencia de los supuestos fácticos considerados en las reglas de los modos de adquirir; problema que se torna especialmente intenso tratándose de los modos de adquirir derivativos, donde la transmisión de la propiedad de un patrimonio a otro supone necesariamente que esta se hubiere encontrado radicada en el patrimonio del transmisor. Esta situación genera un problema social, en la medida que la imposición de un requisito como el descrito impondrá altos costos de transacción a los agentes, expresados en los costos de información en que deberán incurrir en forma previa a participar de un intercambio voluntario destinado a reasignar una titularidad, a fin de corroborar la efectiva existencia de una entidad ideal, como es la propiedad, circunstancia que en definitiva puede llevar a que las reasignaciones que predice el teorema de Coase no se realicen, manteniéndose la propiedad en un uso socialmente menos valioso $^{15}$.

Es por esta razón que los países que integran la tradición jurídica a la cual pertenece el Derecho patrio se han encargado de desarrollar reglas de eminente sentido práctico, destinadas a conferir protección a las reasignaciones en la medida que se satisfaga un supuesto ostensible, como es la posesión. Precisamente, más allá de las largas discusiones doctrinarias sobre la naturaleza de la protección posesoria ${ }^{16}$, es posible encontrar en la interpretación que ha terminado favoreciendo una eminente finalidad práctica, conforme a la cual frente a las exigencias del ordenamiento, el poseedor, por el solo hecho de encontrarse en una posición

\footnotetext{
14 Complementando este análisis, Shavell agrega que la existencia de un derecho de propiedad es también la mejor manera de asegurar una explotación óptima del bien, toda vez que concentrándose todos los incentivos en un solo individuo este podrá decidir conforme a las señales que recibe del mercado hasta donde explotarlo. SHAVELL, Steven, op. cit. (n.12), p. 15.

15 SCHÄFER, Hans-Bernd y Отт, Claus. Manual de Análisis Económico del Derecho Civil. Madrid, España: Tecnos, 1991, p. 332; Posner, Richard, op. cit. (n. 9), pp. 82-84; SHAVell, Steven, op.cit.(n.12), pp. 46 y ss. Bullard GonZÁleZ, Alfredo. "Los Sistemas de Transferencia de Propiedad y la Propiedad Inconclusa". En: Derecho y Economía. El Análisis Económico de las Instituciones Legales - 2a Ed.- Lima, Perú: Palestra Editores, 2010, pp. 161 y ss.

16 Hernández Gil, Antonio. La Posesión como Institución Jurídica y Social. Madrid, España: Espasa-Calpe, 1987, pp. 23-32; Gordley, James. Foundations of Private Law. Proerty, Tort; Contract, Unjust Enrichement. Oxford University Press, 2006, pp. $49-65$.
} 
que habitualmente refleja la existencia de la titularidad, merece protección ${ }^{17}$. Como se ha señalado, es una situación donde se protege la apariencia, por mostrarse esta como lo externamente real ${ }^{18}$. No es difícil de percibir la importancia económica que una regla como la descrita desempeña para el funcionamiento de un sistema de mercado. En efecto, el mercado, como mecanismo de asignación eficiente de los recursos, supone para su funcionamiento la existencia de ciertas condiciones estructurales, dentro de las cuales se encuentra una definición clara de los derechos asignados ${ }^{19}$, siendo esta una problemática que se ve solucionada si el legislador extiende la protección conferida inicialmente en virtud del derecho de propiedad a esta persona que se encuentra en una posición fáctica reconocible por el resto de los agentes del mercado. De esta forma, frente a los riesgos que supone para la reasignación de los bienes la realización del imperativo de justicia contenido en la regla "nadie puede transferir más derechos de los que tiene", el ordenamiento clarifica la existencia de los derechos que serán reasignados, declarando en principio suficiente para gozar de una protección erga omnes (exceptuando, por supuesto, al propietario) la apariencia configurada a la luz de las exigencias del ordenamiento ${ }^{20}$.

Sin embargo, los límites de la protección de esta situación de apariencia se encuadran dentro de los márgenes de las finalidades mismas que persigue el sistema, cobrando especial relevancia la corrección o incorrección del actuar del poseedor. Por esta razón, no es de extrañar que muchos ordenamientos establezcan una protección diferenciada según se trate de una persona que ha iniciado su posesión en la conciencia de haber adquirido la propiedad a través de medios legítimos, o de una que tiene conocimiento de la afectación de otros intereses tutelados a través de su actuar. Se trata, como podrá advertirse, de la clásica distinción entre el poseedor de buena y mala fe.

Contrariamente a lo sostenido habitualmente, existen buenas razones para leer en una clave objetiva la buena fe posesoria ${ }^{21}$ (art. $706 \mathrm{CCch}$ ) dejando de lado una interpretación subjetivista basada en las circunstancias de conocimiento en que se encontraba quien inicia su posesión, partiendo por el hecho que el mismo Código civil atiende para realizar la calificación no solo a aquellos hechos que hubiera efectivamente conocido, sino también a aquellas otras circunstancias que debió conocer. Este último elemento resulta de capital importancia

17 En este sentido, Westermann, Harry, et al. reconocen que "Ciertamente, dentro de ciertos límites, la apariencia de la atribución puede sustituir a veces a la verdadera pertenencia patrimonial”. WESTERMANN, Harry, et al., op. cit. (n. 7), p. 59.

18 HERnÁNDEZ Gil, Antonio, op. cit. (n.16), p. 30.

19 La falta de una definición clara de los derechos asignados obligará a las partes a incurrir en mayores costos de información. Sobre la importancia de los costos de información en el intercambio, NORTH, Douglass. Instituciones, Cambio Institucional y Desempeño Económico. México D.F, México: Fondo de Cultura Económica, 2001. pp. 45 y ss.

20 Como veremos más adelante, si bien es innegable que en la sanción del poseedor de mala fe concurren fuertes argumentos de justicia, las reglas actualmente existentes pueden ser explicadas también desde una perspectiva de bienestar social.

21 GuZmán Brito, Alejandro. "La Buena Fe en el Código Civil de Chile". en: Revista Chilena de Derecho. Vol. 29 N 1 , pp.11-23. Santiago, Chile: Pontificia Universidad Católica de Chile, 2002. 
para la comprensión de la distinción introducida por el Código, toda vez que por su intermedio podemos introducir aquellas exigencias derivadas de las costumbres y los usos del tráfico, las cuales nos permitirán definir, partiendo de un modelo de hombre razonable que resguarda sus propios intereses, qué conductas logran salvar este test de corrección y son por tanto dignas de tutela jurídica ${ }^{22}$. Es precisamente a través de esta visión normativizada de la buena fe que podemos cerrar el sistema, desde el momento que el cumplimiento de las expectativas normativas de corrección por parte del poseedor de buena fe, que hizo lo posible acorde con los usos del tráfico para cerciorarse de la legitimidad de su posición, merece también ser protegida desde una perspectiva económica, desde el momento que la evaluación social destinada a crear la regla de conducta da cuenta de una ponderación, como lo señalaba Learned Hand en su famosa fórmula, entre los costos que está dispuesta a asumir la sociedad para evitar el evento perjudicial y la magnitud de los perjuicios que son esperados ${ }^{23}$.

Habiendo desarrollado el presente marco, que nos permite entender cuál es la importancia económica que tiene la protección de la propiedad y las razones por las cuales el pleno desarrollo de sus finalidades exige la protección de la situación fáctica y aparente que constituye la posesión, nos encontramos en condiciones de poder realizar una nueva mirada a las reglas sobre las prestaciones mutuas.

\section{PRESTACIONES MUTUAS}

Como necesaria consecuencia de la protección a la situación de apariencia generada con la posesión, donde las potestades reconocidas por el ordenamiento al titular de un derecho son ejercidas a título propio por un tercero ${ }^{24}$, recibiendo al menos parcialmente los mismos incentivos que la asignación de un derecho de titularidad exclusiva genera en el propietario, el legislador ha debido regular las consecuencias económicas que las decisiones de inversión y conservación adoptadas generen en la relación patrimonial existente entre estos individuos. Esta temática ha recibido en nuestro ordenamiento la denominación de prestaciones mutuas.

\footnotetext{
22 Por el contrario, una interpretación que mire exclusivamente a la posición en que se encontraba quien inicia su posesión a fin de definir la protectibilidad de su interés, según sus particularidades especiales, no solo afecta las expectativas recíprocas de corrección en el actuar, sino que además genera desincentivos para la generación de información y permite que las personas aleguen sus limitaciones y defectos en su propio beneficio.

23 Adicionalmente, desde una perspectiva económica, debe considerarse que una regla de protección irrestricta de los intereses del propietario genera pocos incentivos para que las personas ejerciten las acciones destinadas a corregir esta clase de situaciones, lo que puede influir en un agravamiento de la situación de incertidumbre. La concurrencia de esta valoración puede llevar en algunos casos a que la posición del poseedor de mala fe pueda ser preferida a la del propietario negligente que no se ocupa de defender sus propios intereses. BoucKaert, BoudeWijn y Depoorter, Ben W.F. "Adverse Possession - Title Systems". En: Encyclopedia of Law \& Economics. <En línea> <http://encyclo.findlaw.com/1200book.pdf>

24 Una consecuencia del elemento animus de la posesión es el no reconocimiento de un derecho de igual contenido perteneciente a otro titular sobre la misma cosa.
} 
Antes de iniciar nuestra interpretación, nos interesa destacar la importancia que desarrolla la existencia de reglas legales completas que permita a los individuos delimitar ex ante sus expectativas protegidas y que proporcionen soluciones exhaustivas a la situación que se genere. En efecto, aunque los individuos en esta situación por definición no enfrentan costos de búsqueda, desde el momento que el nacimiento mismo del conflicto es accesorio a otra relación ${ }^{25}$, de este solo hecho no se sigue que estos se encuentren en una posición que asegure la eficiencia de la decisión de reasignación, cuestión que se explica por el carácter de monopolio bilateral que presenta su relación ${ }^{26}$. Por esta razón, la existencia de reglas completas como las dispuestas por el Código Civil presenta una segunda ventaja, toda vez que evita imponer a las partes la carga de negociar a fin de solucionar el conflicto recurriendo, como veremos a continuación, a una reconstrucción de su relación partiendo de la base de lo que un hombre medio, que participase en ese mercado, estaría dispuesto a contratar ${ }^{27}$, permitiendo en todo caso que estas puedan reasignar los derechos que les reconocen las reglas legales.

Ahora bien, desde antiguo, la explicación que se ha otorgado a esta problemática se encuentra imbuida por las concepciones relacionales de la justicia correctiva propias del problema del enriquecimiento injustificado. Por esta razón no es de extrañar que en el análisis jurídico se hubiere utilizado los criterios desarrollados para los cuasicontratos a fin de justificar las soluciones adoptadas por el legislador chileno, cobrando una especial relevancia la doctrina del enriquecimiento sin causa $^{28}$. Frente a estas explicaciones proponemos una complementaria, basada en los fines propios de los derechos de propiedad.

\subsection{MEJORAS}

Las primeras reglas que debemos explicar son las que delimitan los créditos que nacen en beneficio del poseedor a raíz de las inversiones de conservación que hubiere realizado en

25 Las reglas de las prestaciones mutuas, dispuestas para regular las relaciones entre el poseedor vencido y el dueño con ocasión de la acción reivindicatoria, reciben aplicación en otros casos que la ley las llama a regir, como ocurre con la nulidad, o en aquellos donde no existiendo reglas especiales se dé una problemática similar. AlESSANDRI, Arturo, et al., op. cit. (n. 1), p. 293.

26 Cfr. lo señalado por WONELL respecto de un caso similar, como es la construcción en heredad ajena.

WONNELl Christopher. "Unjust Enrichment and Qusi-Contracts". En: Encyclopedia of Law \& Economics. p. 802. $<$ En línea > http://encyclo.findlaw.com/3900book.pdf >

27 En este sentido, se ha dicho que los Códigos civiles que siguen este tipo de reglas construyen ex post facto un contrato entre las partes. En este sentido, refiriéndose en términos generales a los problemas de intromisión, BASOZAVAL señala que "La condictio por intromisión apunta así hacia un concepción cuasicontractual de la problemática de las acciones intromisivas sobre derechos ajenos, y propone una solución articulada a través de la idea de <contrato fáctico > o comportamiento social típico. El ordenamiento jurídico utiliza a posteriori la idea de contrato para lograr así, una vez producida la irregularidad en el disfrute de los derechos, reequilibrar la situación patrimonial de quien hubiese tenido que <adquirir> en el mercado la facultad usurpada al titular de esta. BESOZABAL ARRUÉ, Xabier. Enriquecimiento Injustificado por Intromisión en Derecho Ajeno. Madrid, España: Civitas, 1998, p. 85.

28 Claro Solar, Luis, op. cit.(n. 2), p. 437. 
una cosa que resultó ser ajena, contenidas en los artículos 908 a 913 del Código Civil. Estas reglas delimitan el grado de protección conferido al poseedor basándose en una doble distinción, según si el poseedor se encuentra de buena o de mala $\mathrm{fe}^{29}$, y según las características propias de estas inversiones.

\subsubsection{Mejoras necesarias}

Donde mejor se puede apreciar la importancia de la justificación estática de la propiedad es en el caso de las mejoras necesarias, correspondientes a aquellas inversiones necesarias para la conservación misma de la cosa. En efecto, para el Código Civil resulta indistinto que estas hubieren sido realizadas por el poseedor que se encontraba de buena o de mala fe, imponiendo siempre al propietario la obligación de compensar la inversión realizada.

Tradicionalmente, se ha entendido que esta regla obedece a un criterio de justicia correctiva, que fundamenta la necesidad de su compensación en el hecho que el propietario igualmente habría debido efectuarlas si la cosa se hubiese encontrado en su poder. Sin embargo, esta explicación nos parece incompleta, en la medida que pone énfasis en la relación personal y no en la valoración misma que la sociedad realiza en orden a la importancia que tiene la conservación de las cosas, circunstancia que fue especialmente considerada por Bello, según se puede leer en el Mensaje del Código Civil, donde refiriéndose a la prohibición de los usufructos sucesivos, expresamente señala la necesidad de resguardar "el espíritu de conservación y mejora, que da vida y movimiento a la industria”.

Como se puede apreciar, en el razonamiento de Bello subyace la idea que los bienes son valiosos y que interesa a toda sociedad su conservación ${ }^{30}$. Por esta razón, podemos decir que la regla que establece la compensación de todas las mejoras necesarias lo que hace es generar los incentivos para realizar las inversiones que exige la conservación de los bienes.

Para corroborar esta afirmación baste considerar la situación más compleja, que es aquella en la que se encuentra el poseedor de mala fe. En efecto, si una persona tiene conocimiento de la precariedad de su posición por la existencia de un mejor derecho radicado en otro titular, ante la falta de una regla que le permita recuperar las inversiones que realice en el bien, solamente podrá adoptar una decisión económicamente razonable, cual es no invertir.

Inclusive, en la forma como se generan los incentivos es posible apreciar la relevancia social que se atribuye a la conservación y la insuficiencia de las concepciones relacionales de

\footnotetext{
29 Económicamente, puede utilizarse la argumentación desarrollada por SHAVELL para evaluar las reglas de protección al tercero de buena fe o de prevalencia del dueño, en la medida que ambas contienen desincentivos a la realización de actividades que importen una afectación de la propiedad ajena. SHAVELL, Steven, op. cit. (n. 12), pp. 53-55.

30 Este principio resulta especialmente intenso tratándose de los bienes inmuebles. ATRIA LEMAITRE, Fernando. "Derechos Reales”, en: Revista de Derecho de la Universidad Adolfo Ibáñez., No 1. pp. 23 y ss. Santiago, Chile: Universidad Adolfo Ibáñez, 2004.
} 
justicia. En efecto, tratándose del poseedor de mala fe nos encontramos con que existen dos incentivos destinados a evitar la decisión de subinversión, como son la compensación de las inversiones y la obligación de reparar los daños provenientes de su negligencia (art. 906 CCch), los cuales funcionan en forma paralela y en los efectos que desarrollan deberían resultar indistintos para el propietario. Pues bien ¿cómo explicar esta situación? La respuesta es simple: si bien ambas tratan de dejar a la víctima en la misma posición, evitando el deterioro o estableciendo su reparación, las reglas de responsabilidad presentan un inconveniente frente a las reglas de propiedad, en la medida que su aplicación se encuentra condicionada a la existencia de un evento material que genera una pérdida de riqueza social, como es la causación del daño, lo que implica la producción de un costo hundido.

Conforme con lo expuesto, la regla que obliga a compensar las mejoras necesarias se justifica como una de las formas en que el legislador promueve los objetivos de conservación que subyacen a la fundamentación estática de la propiedad, presentando una gran ventaja frente a otro tipo de incentivos posibles, como ocurre con las reglas de responsabilidad, desde el momento que su funcionamiento, a diferencia del de estas últimas, no supone la ocurrencia de una pérdida social neta.

\subsubsection{Mejoras útiles}

A diferencia de lo que ocurre con las reglas de las mejoras necesarias, el legislador sí ha establecido diferencias en el tratamiento según si se trate de un poseedor de buena fe o de un poseedor de mala fe. Según lo establecido en los artículos 909 y 910 del Código, el derecho a obtener una compensación solo le es conferido al primero, mientras que el segundo tiene un derecho limitado a poder llevarse los materiales de dichas mejoras ${ }^{31}$, en la medida que este retiro no suponga un detrimento en la cosa reivindicada y que el propietario no esté dispuesto a pagar por ellos. De esta forma, el poseedor de mala fe perderá, sin derecho a compensación alguna, las inversiones que realice en el bien, cuando estas solo impliquen un aumento del valor venal de la cosa.

Tratándose del poseedor de buena fe, la existencia de esta regla de compensación es una consecuencia del reconocimiento de la función atributiva del derecho de propiedad en beneficio del poseedor. Conforme lo expusimos anteriormente, la buena fe del poseedor implica que este se encuentra en una posición que le permite suponer que no existe otra per-

31 Aún en este caso, según señala CLARO SOLAR, su derecho se encuentra sujeto a una limitación económica adicional, desde el momento que, conforme a lo expuesto por el autor "Pero si se trata de materiales que no pueden separarse sin ser los mismos destruidos y que ningún provecho pueden dar; si la separación de estos materiales solo importaría la destrucción de una obra útil al predio, $y$ de la cual ninguna utilidad puede sacar el poseedor que la construyó de la mala fe, no podría invocar la disposición del artículo 910 , el jus tollendi especial que este artículo le concede, para destruir esa obra de la cual no puede retirar materiales aprovechables, para llevárselo". ClaRO SOLAR, Luis, op. cit. (n. 2), p. 449. 
sona con mejor derecho sobre el bien poseído, lo cual a su vez determina que sus decisiones de inversión estarán solamente destinadas a maximizar su propio interés y no a dificultar la restitución a su verdadero propietario. Tomando este argumento en consideración, el Código admite en este caso la compensación de las inversiones realizadas, en la medida que con ella se genera un incremento de la riqueza, expresada en un aumento del valor de mercado de la cosa.

Por el contrario, en una solución que resulta de compleja justificación frente a los imperativos del principio del enriquecimiento sin causa, el Código niega cualquier derecho de compensación al poseedor que debería, conforme a las expectativas sociales, conocer la existencia de una mejor titularidad radicada en otro sujeto sobre el bien poseído. Como podrá apreciarse, la justificación de esta decisión legislativa es compleja, toda vez que la decisión de inversión adoptada por el poseedor incrementará en una medida objetivamente cuantificable el valor del bien. Sin embargo, en contra de esta posible objeción, debemos considerar como errónea una visión que reduzca el concepto de bienestar social y de creación de riqueza a un aumento del valor de los bienes existentes en el mercado, al menos desde una perspectiva económica, desde el momento que la creación de riqueza como lo define el Análisis Económico no depende tanto del aumento del valor de mercado de los bienes, como sí lo hace del aumento de las tasas de bienestar individual. En este sentido, si asumimos que la posición del poseedor de mala fe proviene de una reasignación no voluntaria, que no crea un excedente de cooperación que beneficie a la sociedad, sino que produce meramente un efecto redistributivo, y que la ausencia de una reasignación voluntaria del bien per se nos permite cuestionar que, cuando se encuentre en manos del poseedor, se encontrará asignado a su uso más valioso, nos encontramos con que existen buenas razones económicas para obviar el aumento de valor del bien y simplemente no proteger estas inversiones.

Con todo, la justificación de esta regla no debe limitarse a lo expuesto, siendo necesario considerar adicionalmente, también desde una perspectiva económica, que la defensa de las funciones que desarrolla el derecho de propiedad puede resultar más relevante que la protección de la posición del poseedor, sobre todo cuando el resguardo de esta última implica validar aquellas decisiones que dificultan el derecho del propietario a exigir la restitución ${ }^{32}$, como con notable intuición lo notaba don Luis Claro Solar en sus Instituciones, al señalar que:

"Estando de mala fe no puede invocar que haya hecho esas mejoras como propietario deseoso de mejorar su predio; y es de temer mientras más importantes sean las mejoras, que su intención es dolosa y encaminada a hacer difícil, sino imposible, para el propie-

\footnotetext{
32 Propiamente, se estaría desincentivando el ejercicio de las acciones destinadas a recuperar la posesión, circunstancia que podría determinar un mayor gasto en medidas de cuidado destinadas a evitar su pérdida. v. SHAVELL, Steven, op. cit. (n.12), pp. 38 y ss.
} 
tario la reivindicación, a causa del reembolso a que sería obligado si hubiera de abonar las mejoras hechas antes de la contestación de la demanda"33.

\subsubsection{Mejoras voluptuarias}

Finalmente, en lo que se refiere a las mejoras voluptuarias, el Código nuevamente establece un régimen único para todo poseedor, resultando indistinto que este se encuentre de buena o de mala fe. Acorde con lo señalado, para la aplicación de estas reglas, que niegan al poseedor el derecho de obtener una compensación por las inversiones que realice, solamente se atiende a un criterio objetivo, como lo es la calificación externa de la inversión. Desde una perspectiva económica, esta regla puede ser justificada como una regla de protección al derecho de propiedad, pues facilita el ejercicio de los derechos del propietario evitando que el pago de las compensaciones frustre su pretensión, en circunstancias de que se trata de una inversión que no hubiese sido encomendada por una persona prudente.

De esta forma, cuando nos encontramos en esta situación de falta de relación entre el valor de las inversiones y el aumento de valor de los bienes, el Código protege la posición del propietario y el valor de la autonomía, evitando que se produzca una reasignación de recursos que en condiciones de mercado no se habría producido.

\subsection{FRUTOS}

En lo que se refiere al aprovechamiento de los rendimientos de la cosa, el Código nuevamente distingue entre la situación del poseedor de buena y de mala fe, concediendo solamente al primero el derecho a hacerse de los frutos que hubiere percibido antes de la contestación de la demanda (art. 907 CCch). Para poder entender esta regla, que ha sido interpretada por la doctrina tradicional como una manera de sancionar la mala fe, impidiendo al poseedor obtener provechos de una conducta contraria al ordenamiento, creemos necesario recurrir a los conceptos desarrollados con ocasión de la función atributiva del dominio, de la justificación dinámica del derecho del propiedad y de la protección de la situación de apariencia constituida por la posesión. Sin embargo, como tendremos la oportunidad de apreciar, tratándose de los frutos existe además una consideración adicional que justifica la actual reglamentación, la cual deriva de la importancia social asignada a que las cosas sean efectivamente empleadas.

En lo que respecta a la posición del poseedor de buena fe, es posible advertir con mayor intensidad como la situación de apariencia expresada en la posesión justifica la atribución

33 Claro Solar, Luis, op. cit. (n. 2). p. 415. 
de derechos similares a los reconocidos al propietario. Mediante este reconocimiento, la legislación asegura el desarrollo de los objetivos perseguidos a través de la justificación dinámica de la propiedad, asignando al poseedor (quien es la persona que se encuentra en mejor situación fáctica para realizar las inversiones que requiere la explotación de la cosa, toda vez que esta se encuentra bajo su esfera de control) los mismos incentivos que confiere al propietario. En estos términos, si el poseedor ha cumplido con las exigencias destinadas a resguardar la legitimidad de su posición, podrá posteriormente realizar todas las actuaciones de inversión que son inherentes al propietario, desde el momento que tendrá un derecho sobre los resultados de su inversión, todo lo cual conduce, en definitiva, a que la decisión de inversión no se encontrará limitada por la necesidad de realizar nuevas averiguaciones que aseguren la inexistencia de un titular con mejor derecho a quedarse con los frutos.

Sin embargo, la justificación desde la perspectiva económica no puede verse constreñida a un asunto de creación de incentivos para la inversión, desde el momento que en una simplificación de las reglas contenidas en las Partidas, el Código eliminó el requisito de la realización de una inversión previa como condición de apropiabilidad de los frutos ${ }^{34}$. Pues bien ¿cómo puede justificarse la modificación que realizó Bello, en circunstancias que los frutos naturales no exigen la realización de ningún trabajo para su obtención? En nuestro concepto, se trata de una manera de fortalecer el derecho del poseedor y de disminuir los costos de transacción, clarificando la asignación de los derechos ${ }^{35}$.

En resumidas cuentas, en todo lo que se refiere a los frutos, para efectos de funcionamiento del sistema de transacciones, la posesión de buena fe desarrolla las funciones de la propiedad.

Por el contrario, tratándose del poseedor de mala fe, concurren buenas razones para negar los efectos que si se reconocen al poseedor de buena fe, que van desde el hecho que él carece de la expectativa de no ver turbada su posición jurídica, hasta el desincentivo de las conductas de apropiación. Sin embargo, la existencia de estas reglas puede generar un problema de incentivos para la explotación de los bienes, desde el momento que la ausencia de una regla que permita al poseedor de mala fe hacerse de los frutos hará que la decisión que mejor satisfaga su interés sea simplemente no hacer nada, dejando de realizar cualquier inversión destinada a la explotación del bien.

Contrariamente a lo que podría pensarse, el Código Civil, con notable intuición, soluciona este problema. Como anticipáramos, existe un especial interés social recogido por el Código, no siendo aceptable que los bienes, pudiendo ser explotados, no lo sean, toda vez

\footnotetext{
34 Claro Solar, Luis, op. cit. (n. 2).p. 433 y ss.

35 Considérese, por ejemplo, lo que ocurriría con la trasferencia de los frutos si el poseedor que dispone de ellos no cuenta en realidad con un derecho de propiedad sobre ellos.
} 
que ello importará que se dejen de producir recursos socialmente necesarios ${ }^{36}$. Por esta razón, nuestra legislación establece una sanción especial al poseedor de mala fe, a fin de evitar que su inactividad prive a la sociedad de recursos que podrían generarse, haciéndolo responsable de aquellos frutos que el dueño hubiere podido percibir con mediana inteligencia y actividad, si la cosa se encontrase en su poder (art. 907 CCch), solucionando de esta forma el problema de la falta de incentivos para producir, desde el momento que las opciones de que dispondrá el poseedor de mala fe será invertir y realizar una inversión destinada a explotar la cosa, caso en el cual deberá los frutos a su propietario (una vez deducidos los gastos ordinarios empleados en su producción) o no invertir y pagar al propietario el valor de los rendimientos no percibidos.

\subsection{IMPORTANCIA DE LA DELIMITACIÓN DEL MOMENTO A PARTIR DEL CUAL SE CONSIDERARÁ DE MALA FE AL POSEEDOR}

En materia de prestaciones mutuas, el Código establece una regla especial de carácter correctivo en el artículo 913 CCch, fijando como momento en el cual debe considerarse la buena o mala fe del poseedor no aquel en que se haya iniciado la posesión, sino aquel en que se adopte la decisión de inversión o de aprovechamiento, lo cual se encuentra en concordancia con los incentivos que subyacen a las reglas de mejoras y de frutos.

\subsection{PROBLEMA NO ABORDADO POR LAS REGLAS DE LAS PRESTACIONES MUTUAS}

Finalmente, un problema no abordado por las reglas de las prestaciones mutuas es como la situación de conocimiento del dueño del bien puede afectar la forma como se regulan las compensaciones a que tiene derecho cada una de las partes, cuestión que, más allá de los problemas éticos (que damos por supuestos), puede además generar problemas económicos, como la ausencia de un incentivo para mitigar los daños o, inclusive, la creación de un incentivo a generar información incorrecta sobre la titularidad del bien a fin de obtener un beneficio económico ${ }^{37}$.

Frente a esta situación, no solucionada expresamente, nos parece que la mejor solución desde una perspectiva económica es aplicar por analogía las reglas sobre la accesión, las cua-

\footnotetext{
36 Este argumento fue desarrollado por Hugo GROCIO, para quien, si bien conforme a la justicia conmutativa los frutos de los bienes deben ir a su dueño, el fundamento último de los recursos es que estos sean usados, lo que lo llevó a argumentar que los no dueños disponían de un derecho de uso inocente, un derecho a usar la propiedad de otro en la medida que no ocasionaran perjuicios a su dueño. Todo esto lleva a GORDLEY a afirmar que la fundamentación de la protección posesoria y el reconocimiento del derecho del poseedor a hacerse de los frutos puede encontrarse, en aquellos casos en que el dueño se encuentra desprovisto de la posibilidad de explotar sus bienes, en que es preferible que alguien obtenga un provecho por la explotación de los bienes antes que desperdiciar estos recursos. GORDLEY, James, op. cit. (n. 16), pp. 63-64.

37 BOUCKAERT, Boudewijn y DePOORTER, Ben, op. cit. (n. 23), p. 21.
} 
les, encontrándose referidas a un problema asimilable al existente en la reivindicación, imponen al dueño deberes especiales de autocuidado que minimizan el riesgo moral, entendiendo su inactividad, en circunstancias que se encontraba en conocimiento de la apropiación de sus bienes por un tercero, lo cual implica una voluntad de negociar la transferencia de los bienes, completándose ex post la información relativa a las condiciones del intercambio recurriendo a una integración conforme a las condiciones de mercado (art. 666 y 669 inciso final CCch).

\section{CONCLUSIONES}

El desarrollo de este trabajo introductorio nos ha permitido realizar una primera mirada a los objetivos sociales que subyacen a las reglas de las prestaciones mutuas, pudiendo apreciar cómo es posible identificar una racionalidad económica subyacente a su regulación, y que se expresa por la necesidad que existe de ampliar el sistema de incentivos que establece el derecho de propiedad a individuos que, sin contar estrictamente con una atribución de titularidad sobre el bien que poseen, se encuentran en una situación de apariencia que debe ser protegida a fin de reducir los costos de transacción. Esta exigencia, dentro del sistema del Código Civil, resulta especialmente intensa tratándose de la evitación de las decisiones de subinversión en la conservación, circunstancia que puede ser explicada por la opción adoptada por la sociedad en orden a evitar la destrucción de los bienes. Sin embargo, lo que resultó más interesante fue advertir que, en forma paralela a las justificaciones económicas basadas en la maximización del bienestar social y en las justificaciones de principios basados en la necesidad de proteger el comportamiento considerado socialmente correcto, es posible advertir que en determinadas ocasiones el Código Civil confiere prevalencia a un valor que puede diferir de los señalados anteriormente, cual es la importancia que se asigna socialmente a la utilización de los bienes. Por último, como podrá apreciarse de este recuento, resulta inconcuso que las reglas sobre las prestaciones mutuas no admiten una única justificación, cuestión que exige una labor para el intérprete, quien deberá previamente identificar las diversas valoraciones de resultado y de principio que subyacen a estas reglas, y la manera como estas se pueden ver afectadas en la aplicación práctica que se realice de esta normativa, a fin de otorgar una solución socialmente correcta. 


\section{REFERENCIAS BIBLIOGRÁFICAS}

Alessandri Rodríguez, Arturo. et al. Tratado de los Derechos Reales -6a Edición- Santiago, Chile: Editorial Jurídica de Chile, 1997.

Besozabal ARruÉ, Xabier. Enriquecimiento Injustificado por Intromisión en Derecho Ajeno. Madrid, España: Civitas, 1998.

BOUCKAERT, Boudewijn y DePOORTER, Ben W.F. "Adverse Possession - Title Systems". En: Encyclopedia of Law \& Economics. <En línea>.[Consulta el 3 de septiembre de 2010] Disponible en World Wide Web: <http:// encyclo.findlaw.com/1200book.pdf>

Bullard GonZÁlez, Alfredo. "Los Sistemas de Transferencia de Propiedad y la Propiedad Inconclusa”. En: Derecho y Economía. El Análisis Económico de las Instituciones Legales - 2a Ed.- Lima, Perú: Palestra Editores, 2010.

CAlabresi, Guido y Melamed, Douglas. "Reglas de Propiedad, Reglas de Responsabilidad y de Inalienabilidad: Una Vista de la Catedral” en: Estudios Públicos N 63. Santiago, Chile: Centro de Estudios Públicos, 1996.

Claro Solar, Luis. Explicaciones de Derecho Civil Chileno y Comparado. Santiago, Chile: Editorial Nascimento, 1935.

Coleman, Jules. La Concepción Mixta de la Justicia Correctiva. En: Rosenkrantz, Carlos. Compilador. La Responsabilidad Extracontractual. Barcelona, España: Editorial Gedisa, 2005.

Cooter, Robert y Ulen, Thomas. Derecho y Economía. México D.F. México: Fondo de Cultura Económica, 1998.

Gordley, James. Foundations of Private Law. Proerty, Tort; Contract, Unjust Enrichement. Oxford University Press, 2006.

GuZmán Brito, Alejandro. "La Buena Fe en el Código Civil de Chile”. en: Revista Chilena de Derecho. Vol. 29 $\mathrm{N}^{\circ}$ 1. Santiago, Chile: Pontificia Universidad Católica de Chile, 2002.

Hernández GIL, Antonio. La Posesión como Institución Jurídica y Social. Madrid, España: Espasa-Calpe, 1987.

NorTH, Douglas. Instituciones, Cambio Institucional y Desempeño Económico. México D.F., México: Fondo de Cultura Económica, 2001.

Peñailillo Arévalo, Daniel. "Enriquecimiento sin Causa. Principio de Derecho y Fuentes de Obligaciones" en: Revista de Derecho Universidad de Concepción. No 200. Concepción, Chile: Universidad de Concepción, 1996. 2009.

Posner, Richard. El Análisis Económico del Derecho. México D.F., México: Fondo de Cultura Económica, 1998.

Ríos LabBÉ, Sebastián. "Ciento Cincuenta Años de Evolución del Derecho de Propiedad”. En: MarTINIC, María Dora; et al. Sesquicentenario del Código Civil de Andrés Bello. Pasado, Presente y Futuro de la Codificación. Tomo I. Santiago, Chile: LexisNexis, 2005.

Rozas Vial, Fernando. Los Bienes -3a Ed.- Santiago, Chile: LexisNexis, 2004.

SCHÄFER, Hans-Bernd y Ott, Claus. Manual de Análisis Económico del Derecho Civil. Madrid, España: Tecnos, 1991.

SHAVELL, Steven. Foundations of Economic Analysis of Law. Cambridge, Massachussetts: The Belknap Press of Harvard University Press, 2004

Tapia Rodríguez, Mauricio. Código Civil 1855-2005. Evolución y Perspectivas. Santiago, Chile: Editorial Jurídica de Chile, 2005.

Westermann, Harry et al. Derechos Reales. Volumen I -7a Ed.- Madrid, España: Fundación Cultural del Notariado, 1998. 
Pablo Cornejo Aguilera / Una nueva mirada a las prestaciones mutuas

Wonnell, Christopher. "Unjust Enrichment and Qusi-Contracts". En: Encyclopedia of Law \& Economics. <En línea >. Disponible en World Wide Web: <http://encyclo.findlaw.com/3900book.pdf>

Zimmermann, Reinhard. Estudios de Derecho Privado Europeo. Madrid, España: Civitas, 2000. 